\title{
a \\ Risk factors of hearing defects and their relationship to the outcome of hearing screening among neonates
}

\author{
DOI: https://doi.org/10.32007/89744-49
}

\author{
Numan N. Hameed* (MD, FRCPCH, FIBMS, MRCPCH) \\ Mokhalad G. Malih** (MD, MBChB)
}

\section{(1) (8)}

This work is licensed under a Creative Commons Attribution-NonCommercial 4.0 International License.

\begin{abstract}
:
JFac Med Baghdad

2019; Vol.61, No.1

Received: April, 2019

Accepted: June 2019

Published: July, 2019 respectively.

\section{Introduction:}

Hearing loss (HL) is one of the common congenital problems among neonates [1]. The prevalence of significant HL ranges from 1.2 per 1,000 healthy newborn infants and 2 to $5 \%$ in high-risk newborns $[2,3]$. Nearly $50 \%$ of congenital HL is due to genetic defects [1]. About 50\% of hearing defects can be detected in a selective screening based exclusively on hearing risk criteria [1]. Early detection and intervention at a younger age are critical for future speech, language and cognitive development. Neonates with congenital HL should be identified within the first 3 months of life. However, the average age at detection is currently 24-30 months [4]. Hearing assessment can be done either by Transient evoked Otoacoustic emission (TEOAE) or by Automated Auditory Brainstem Response (AABR). OAEs provide a simple, efficient and non-invasive objective indicator of healthy cochlear function. OAEs may be either spontaneous or induced by acoustic stimulation. TEOAE is an effective method for neonatal audiological screening both in the general population and in high-risk infants [5]
\end{abstract}

Background: Increased exposure to risk factors of hearing loss leads to a high susceptibility to deafness among neonates admitted to neonatal care units in developing countries.

Objective: This article aims to study the prevalence of risk factors for neonatal hearing defect and determine their effect on the result of transient evoked otoacoustic emissions hearing test (TEOAE).

Methods: A longitudinal study was carried out for a period of one year from $1^{\text {st }}$ October, 2016 to $30^{\text {th }}$ September, 2017 in the CWTH, Medical city, Baghdad, Iraq. Demographic characteristics and certain risk factors were recorded for screened neonates. TEOAE test was done and if they failed to pass two steps, they were referred to automated auditory brainstem-response (AABR).

Results: Out of 400 neonates, $342(85.5 \%)$ passed from step 1 TEOAE, while $58(14.5 \%)$ were referred to step 2. From 58, $26(44.8 \%)$ have passed step 2 and 32 (55.2\%) not pass step 2 and were referred to AABR. From those 32 neonates with suspected hearing defect, NICU stay $>7$ days, ototoxic drugs $>7$ days, use of ventilator $>7$ days, birth weight $<1500 \mathrm{gm}$, and craniofacial malformations were the main risk factors for hearing defects occurring in (90.6\%), (90.6\%), (59.4\%), (40.6\%), and (21.9\%)

Conclusions: Low birth weight, long intensive care stay, mechanical ventilation, drugs ototoxicity and craniofacial malformation of neonates are the main risk factors for failed TEOAE test.

Keywords: Hearing defect, Hearing Screening, Neonates, Risk Factors.

* Department of Pediatrics, College of medicine, Baghdad University.

Correspondence

Email:numanalhamdani@Yahoo.com

** Children welfare teaching hospital, medical city.

Email: m_g_plus@yahoo.co.uk
Risk factors associated with HL were identified by the Joint Committee on Infant Hearing ( JCIH) in 2007 [6]. The use of risk factors is no longer recommended to select children who should undergo hearing screening. Studies have shown that only $50 \%$ of the pediatric population with congenital HL would be identified by this procedure. However, it is essential to identify risk factors for HL, because an infant with any of these factors in neonatal history has a greater chance of experiencing HL. Additionally, it can guide the approach to be adopted after the results of the hearing screening [7]. Newborn hearing screening was initially targeted toward those newborn " 'at risk" for HL called High-Risk Register (HRR) [6].This group included infants who had asphyxia, meningitis, congenital or perinatal infections, anatomic defects or stigmata, hyper-bilirubinemia, family history of HL, low birth weight, ototoxic medications, and neonatal illnesses requiring mechanical ventilation. HRR screening resulted in around $50 \%$ of congenital HL being undetected [8]. It was soon realized that a more logical approach is to implement universal newborn hearing screening aiming at the early identification of most, if not all children with congenital HL[9]. This study Aimed to find out the prevalence of risk factors for neonatal $\mathrm{HL}$ and determine their relationship the result of TEOAE hearing test in neonates referred and admitted to NICU of Children Welfare Teaching Hospital, Medical City, Baghdad. 


\section{Patients and Methods:}

A longitudinal study was carried out for the period from $1^{\text {st }}$ October, 2016 to $30^{\text {th }}$ September, 2017 in the CWTH, Medical city, Baghdad, Iraq. This 250 beds tertiary hospital had 34 incubators and a level 3Neonatal Intensive Care Unit (NICU) which receives infants referred from other hospitals, primary health centers and private clinics for further management of neonates. Inclusion criteria include all neonates less than 28 days old who were referred to hospital for screening from other NICUs and discharged well. Exclusion criteria included neonates who failed in the step 1 of screening and have not attended the second one, and those whose parents refused participation due to deteriorated health status. Data was collected from the parents and the neonates' discharge cards in the outpatient neonatology clinic and case sheets of neonates admitted to NICU/CWTH through direct interview and filling the prepared data collection sheet. The data collection sheet was designed by the researchers depending on the experience of previous international literatures. The questionnaire included the followings: Demographic characteristics, age and gender of neonates, gestational age of neonates, gestational history, type of delivery, birth weight, consanguinity and craniofacial malformations, family history of HL, clinical history, NICU stay duration, sepsis, meningitis, use of ventilator, ototoxic drugs, hyperbilirubinemia and exchange transfusion, Results of step 1-TEOAE, and results of step 2TEOAE. After identifying eligible neonates, their data was collected and a TEOAE hearing test was performed by a well-trained healthcare provider. Neonates who have passed the $1^{\text {st }}$ step were considered normal. The $2^{\text {nd }}$ TEOAE test was performed after two weeks for a neonate who had failed the $1^{\text {st }}$ test. They were referred to AABR to complete the assessment of their hearing if they failed the $2^{\text {nd }}$ TEOAE hearing test. TEOAE test was carried out for both ears using the ILO Echo-check system, a portable device which uses click stimuli involving frequency bands between $1,500 \mathrm{~Hz}$ and $3,800 \mathrm{~Hz}$. The click is presented at an intensity of 75 to $83 \mathrm{dBpeSPS}$. The response was considered positive (pass) when the otoacoustic emissions captured were $6 \mathrm{~dB}$ higher than the noise. Approval to conducts the study was obtained from the Ethical committee of CWTH. Oral informed consent was taken from neonates' parents by the health care provider. The neonates were screened as part of the hospital policy to screen all neonates who came to CWTH neonatology outpatient clinic and admitted neonates to NICU before discharge. The data of screening were collected from registry of hearing screen room.

\section{Statistical analysis:}

All patients' data were analyzed using Statistical Package for Social Sciences (SPSS) version 22. Descriptive statistics were presented as (mean \pm standard deviation) and frequencies / percentages. Kolmogorov Smirnov analysis verified the normality of the data set. Chi square test was used test the association between categorical data (Fishers exact probability test was used when expected variables were less than $20 \%$ of total). Independent sample ttest was used to compare between two means. The level of significance ( $p$ value) was set at $\leq 0.05$.

\section{Results:}

A total of 400 neonates screened for $\mathrm{HL}$ were included with mean age of $19 \pm 8$ days. Two-hundred and thirty $(57.5 \%)$ screened neonates were males and $170(42.5 \%)$ were females with male to female ratio of $1.3: 1$. The mean gestational age (GA) was $35.3 \pm 3.3$ weeks; 4 neonates $(1 \%)$ were born before 28 weeks of gestation, $34(8.5 \%)$ were $28-<32$ weeks of GA, $208(52 \%)$ were $32-<37$ weeks of GA and 154 $(38.5 \%)$ were $\geq 37$ weeks of G.A. of 400 screened neonates, $161(40.2 \%)$ were delivered vaginally (VD), while $239(59.8 \%)$ were delivered by cesarean section (CS). Birth weight less than $1500 \mathrm{~g}$ was found in 95 neonates $(23.7 \%)$. Consanguinity was found in $204(51 \%)$. Craniofacial malformations were found in 30 neonates $(7.5 \%)$. A positive family history of $\mathrm{HL}$ was found in 22 neonates $(5.5 \%)$. The mean NICU stay duration was $11 \pm 6$ days, $128(32 \%)$ neonates stayed $\leq 7$ days and $272(68 \%)$ had stayed more than 7 days. History of sepsis was present in 171 (42.8\%), meningitis in $34(8.5 \%)$, on ventilation $>7$ days in 70 $(17.5 \%)$, on ototoxic drugs $>7$ days in $271(67.8 \%)$, significant hyperbilirubinemia in $216(54 \%)$ and requiring exchange transfusion in40 (10\%) of neonates (Table 1).

Table 1: Clinical history of $\mathbf{4 0 0}$ neonates

\begin{tabular}{lll}
\hline Variable & No. & $\%$ \\
\hline NICU stay duration mean \pm SD $(11 \pm 6$ days $)$ & & \\
\hline$\leq 7$ days & 128 & 32.0 \\
\hline$>7$ days & 272 & 68.0 \\
\hline Sepsis & 171 & 42.8 \\
\hline Meningitis & 34 & 8.5 \\
\hline Ventilator $>7$ days & 70 & 17.5 \\
\hline Ototoxic drugs $>7$ days & 271 & 67.8 \\
\hline Significant hyperbilirubinemia & 216 & 54.0 \\
\hline Exchange transfusion required & 40 & 10.0 \\
\hline Total & 400 & 100.0 \\
\hline
\end{tabular}

Of 400 screened neonates, $342(85.5 \%)$ passed step 1 TEOAE while 58(14.5\%) were referred to step 2 TEOAE. Of those 58 neonates referred to step 2 TEOAE, $26(44.8 \%)$ have passed step 2 while 32 $(55.2 \%)$ have failed it and were referred to AABR. Neonates referred to AABR represented $32(8 \%)$ of total screened neonates. There was no significant association between gender and being referred to AABR. A significant association was found between referral to AABR and lower GA ( $\mathrm{p}=0.02)$ (Table 2). 
hearing screening among neonates.

Table 2: Distribution of neonates' gender and gestational age according to TEOAE passing (No AABR) and referral to AABR

\begin{tabular}{|c|c|c|c|c|c|c|c|}
\hline \multirow[t]{2}{*}{ Variable } & \multicolumn{2}{|c|}{ AABR } & \multicolumn{2}{|c|}{ No AABR } & \multirow[t]{2}{*}{ Total } & \multirow[t]{2}{*}{$\chi^{2}$} & \multirow[t]{2}{*}{$\mathrm{P}$} \\
\hline & No. & $\%$ & No. & $\%$ & & & \\
\hline \multicolumn{6}{|l|}{ Gender } & \multirow[t]{3}{*}{0.2} & \multirow[t]{3}{*}{0.6} \\
\hline Male & 17 & 7.4 & 213 & 92.6 & 230 & & \\
\hline Female & 15 & 8.8 & 155 & 91.2 & 170 & & \\
\hline \multicolumn{6}{|c|}{ Gestational age } & \multirow[t]{5}{*}{$9.8^{*}$} & \multirow{5}{*}{$\begin{array}{l}0.02 \\
\text { Signi- } \\
\text { ficant }\end{array}$} \\
\hline$\geq 37$ & 10 & 6.5 & 144 & 93.5 & 154 & & \\
\hline $32-<37$ & 14 & 6.7 & 194 & 93.3 & 208 & & \\
\hline $28-<32$ & 7 & 20.6 & 27 & 79.4 & 34 & & \\
\hline$<28$ & 1 & 25.0 & 3 & 75.0 & 4 & & \\
\hline
\end{tabular}

No significant associations were detected between neonates being referred to AABR and the type of delivery, consanguinity and family history of HL. A significant association between low birth weight and referral to AABR ( $\mathrm{p}=0.01)$ was detected as well as a highly significant association between craniofacial malformation and referral to AABR $(\mathrm{p}<0.001)$, (Table 3).

Table 3: Distribution of obstetrical and family history according to TEOAE passing (No AABR) and referral to $\mathrm{AABR}$

\begin{tabular}{|c|c|c|c|c|c|c|c|}
\hline \multirow[t]{2}{*}{ Variable } & \multicolumn{2}{|c|}{ AABR } & \multicolumn{2}{|c|}{ No AABR } & \multirow{2}{*}{$\begin{array}{l}\text { Tota } \\
1\end{array}$} & \multirow[t]{2}{*}{$\chi^{2}$} & \multirow[t]{2}{*}{$\mathrm{P}$} \\
\hline & No & $\%$ & No. & $\%$ & & & \\
\hline \multicolumn{6}{|c|}{ Type of delivery } & \multirow[t]{3}{*}{0.6} & \multirow[t]{3}{*}{0.4} \\
\hline Vaginal & 15 & 9.3 & 14 & 90.7 & 161 & & \\
\hline $\mathrm{CS}$ & 17 & 7.1 & 22 & 92.9 & 239 & & \\
\hline \multicolumn{6}{|c|}{ Birth weight $<1500 \mathrm{gm}$} & \multirow[t]{3}{*}{5.4} & \multirow{3}{*}{$\begin{array}{l}0.01 \\
\text { Sig }\end{array}$} \\
\hline Yes & 13 & 13. & 82 & 86.3 & 95 & & \\
\hline No & 19 & 6.2 & 28 & 93.8 & 305 & & \\
\hline \multicolumn{6}{|c|}{ Consanguinity } & \multirow[t]{3}{*}{0.3} & \multirow[t]{3}{*}{0.5} \\
\hline Positive & 18 & 8.8 & 18 & 91.2 & 204 & & \\
\hline Negativ & 14 & 7.1 & 18 & 92.9 & 196 & & \\
\hline \multicolumn{6}{|c|}{ Craniofacial malformation } & \multirow{3}{*}{$\begin{array}{l}10.3 \\
*\end{array}$} & \multirow{3}{*}{$\begin{array}{l}0.00 \\
1 \\
\text { High }\end{array}$} \\
\hline Yes & 7 & 23. & 23 & 76.7 & 30 & & \\
\hline No & 25 & 6.8 & 34 & 93.2 & 370 & & \\
\hline \multicolumn{6}{|c|}{ Family history of hearing loss } & \multirow[t]{3}{*}{$2.1^{*}$} & \multirow[t]{3}{*}{0.1} \\
\hline Positive & 0 & 0 & 22 & 100. & 22 & & \\
\hline Negativ & 32 & 8.5 & 34 & 91.5 & 378 & & \\
\hline
\end{tabular}

*Fishers exact propability test

There was no significant association between neonates being referred to AABR and having sepsis, meningitis, hyperbilirubinemia and exchange transfusion. There was a significant association between referral to AABR and increased NICU stay duration $(p=0.004)$, neonates on ventilator for $>7$ days $(\mathrm{p}<0.001)$ and ototoxic drugs use for $>7$ days $(\mathrm{p}=0.004)$, (Table 4).

Table 4: Distribution of neonates' clinical history according to TEOAE passing (No AABR) and referral to AABR

\begin{tabular}{|c|c|c|c|c|c|c|c|}
\hline \multirow[t]{2}{*}{ Variable } & \multicolumn{2}{|c|}{ AABR } & \multicolumn{2}{|c|}{ No AABR } & \multirow[t]{2}{*}{ Total } & \multirow[t]{2}{*}{$\chi^{2}$} & \multirow[t]{2}{*}{$\mathrm{P}$} \\
\hline & $\mathrm{No}$ & $\%$ & No. & $\%$ & & & \\
\hline \multicolumn{6}{|c|}{ NICU stay duration } & \multirow[t]{3}{*}{8.1} & \multirow{3}{*}{$\begin{array}{l}0.004 \\
\text { Sig }\end{array}$} \\
\hline$\leq 7$ days & 3 & 2.3 & 125 & 97.7 & 128 & & \\
\hline$>7$ days & 29 & 10.7 & 243 & 89.3 & 272 & & \\
\hline \multicolumn{6}{|l|}{ Sepsis } & \multirow[t]{3}{*}{2.5} & \multirow[t]{3}{*}{0.1} \\
\hline Yes & 18 & 10.5 & 153 & 89.5 & 171 & & \\
\hline No & 14 & 6.1 & 215 & 93.9 & 229 & & \\
\hline \multicolumn{6}{|l|}{ Meningitis } & \multirow[t]{3}{*}{0.03} & \multirow[t]{3}{*}{0.8} \\
\hline Yes & 3 & 8.8 & 31 & 91.2 & 34 & & \\
\hline No & 29 & 7.9 & 337 & 92.1 & 366 & & \\
\hline
\end{tabular}

\begin{tabular}{|c|c|c|c|c|c|c|c|}
\hline Yes & 19 & 27.1 & 51 & 72.9 & 70 & \multirow[t]{2}{*}{42.2} & $<0.001$ \\
\hline No & 13 & 3.9 & 317 & 96.1 & 330 & & High \\
\hline \multicolumn{6}{|c|}{ Ototoxic drugs $>7$ days } & \multirow[t]{3}{*}{8.3} & 0.004 \\
\hline Yes & 29 & 10.7 & 242 & 89.3 & 271 & & Sig \\
\hline No & 3 & 2.4 & 126 & 97.6 & 129 & & \\
\hline \multicolumn{6}{|c|}{$\begin{array}{l}\text { Hyperbilirubinemia requiring phototherapy or } \\
\text { exchange transfusion }\end{array}$} & \multirow[t]{3}{*}{0.4} & \multirow[t]{3}{*}{0.5} \\
\hline Yes & 19 & 8.8 & 197 & 91.2 & 216 & & \\
\hline No & 13 & 7.1 & 171 & 92.9 & 184 & & \\
\hline \multicolumn{6}{|c|}{ Exchange transfusion required } & \multirow[t]{3}{*}{0.01} & \multirow[t]{3}{*}{0.9} \\
\hline Yes & 3 & 7.5 & 37 & 92.5 & 40 & & \\
\hline No & 29 & 8.1 & 331 & 91.9 & 360 & & \\
\hline
\end{tabular}

\section{Discussion:}

Completeness of children auditory system is an essential requirement and one of the prerequisites for earning a complete oral language and intellectual development by communicating with their families, understanding the world, interaction with other children, thoughts and feeling development and acquisition of knowledge [10]. In the current study 32 (8\%) of the neonates were referred to AABR after screening with two steps of TEOAE. This prevalence of suspected HL is close to results of Oliveira et al in Brazil who reported that among 1146 screened neonates, $82(7.2 \%)$ failed TEOAE and were referred to AABR [11]. The prevalence is higher than that found by Gouri et al in India (5.3\%) [12], but lower than that found by Pourarian et al in Iran (13.7\%) [13] and Olusanya et al in Nigeria (4.1\%) [14]. High prevalence of suspected neonates with HL might be attributed to the fact that CWTH is a tertiary center mainly receiving complicated cases from other governorates. The current study revealed 58 (14.5\%) neonates were referred to step-2 TEOAE, from whom $32(55.2 \%)$ were referred to AABR. These findings are higher than the results of Habib et al in Saudi Arabia[15], who found that among 11986 neonates screened with step 1-TEOAE, 1043 (8.7\%) neonates were referred to step- 2 TEOAE, from whom 300 (27\%) failed and were referred to AABR. The higher rate of referrals to step-2 TEOAE test (false positive step-1) could be due to local causes like wax accumulation or otitis media (with or without effusion) or due to an improper external environment like noise. Kumar et al[16] stated that TEOAE had a high accuracy in early detection of congenital HL, in spite of the high false negative rate found by many studies.[17,18] TEOAE has limited activity in the categorization of risk factors for $\mathrm{HL}$ among high risk population[19] in addition to many disadvantages of screening use among neonates [16,20]. Despite these findings, TEOAE represents the major non-invasive instrument for early detection of $\mathrm{HL}$ of cochlear origin, as it focuses on mechanical function in addition to TEOAE cost-effectiveness that facilitates its application in developing countries.[21] Low GA of neonates was significantly associated with failed step-2 TEOAE hearing test $(\mathrm{p}=0.02)$. This finding coincides with the results of Waters et al [22] in the USA. Infants born with lower GA were exposed to delayed myelination of the central nervous system and hearing bones development [23]. Some studies suggested that the main causes of hearing impairment among low GA infants are cochlear immaturity in 
hearing screening among neonates.

pre-term neonates and middle ear effusion due to prolonged tracheal intubation $[16,18]$. Similarly, the current study showed a significant association between low birth weight $(<1500 \mathrm{gm})$ and failed step2 TEOAE $(\mathrm{p}=0.01)$. This finding is consistent with results of Onoda et al in Brazil [24]. Many authors found a strong relationship between birth weight and failed hearing screening tests in addition to HL[25].The very low birth weight has multiple risk factors for hearing problems like birth asphyxia which needs long NICU admission, mechanical ventilation and ototoxic medications[26]. Gender of the neonate was not significantly associated with failing TEOAE. This finding is similar to results of Karaca et al in Turkey[27].Consanguinity and family history of HL were not found to be related to neonatal hearing problems, in contrast to the results of Shrikrishna et al in India who reported that consanguinity and family history are common risk factors of genetic neonatal HL[28]. Neonates with craniofacial malformations had significantly higher rates of failed TEOAE $(\mathrm{p}=0.001)$, similar to report of Lunardi et al in Italy [29]. Craniofacial malformation is related mainly to developmental abnormalities of the first and second branchial arches, which contribute to development of the hearing system (skeletal, muscular and nervous) [29]. NICU stay duration was significantly related to failed TEOAE hearing tests $(\mathrm{p}=0.004)$, in consistence with the results of Barboza et al in Brazil [30]. Long NICU stay duration is usually relevant to deteriorated health of infants, prematurity, mechanical ventilation and ototoxic antibiotic use [31]. Use of ventilators for more than 7 days was significantly related to failed TEOAE screening test $(\mathrm{p}<0.001)$, in consistence with results of Amini et al in Iran [32]. Continuous nasal positive airway pressure applied as a respiratory support for preterm neonates proved to be a risk factor for prolonged exposure to high levels of noise [33]. The current study revealed that ototoxic drugs used for neonates were significantly associated with failed TEOAE screening $(\mathrm{p}=0.004)$, which is in agreement with the results of So et al in the USA [34], who documented that the use of bolus doses of ototoxic drugs especially aminoglycosides is highly related with neonatal $\mathrm{HL}$ and that over therapeutic serum levels of aminoglycosides have shown an increased possibility of ototoxicity. Since aminoglycoside serum concentrations were not measured in our study, there is a high probability that those neonates who had failed TEOAE screening might have had high serum levels while receiving aminoglycosides and eventually had an increased risk of ototoxicity, especially when these drugs were given for long periods. The concern of many literatures was the delayed effect of aminoglycosides in development of sensory neural HL [35]. Although no significant relationship was demonstrated between failing TEOAE and each of sepsis, meningitis, hyperbilirubinemia and exchange transfusion, many studies had reported neonatal sepsis and high bilirubin level of neonates as independent risk factors for HL among neonates [36, 37]. This inconsistency with our findings might be due to differences in health services in addition to differences in study design.

\section{Conclusions:}

Prematurity, low birth weights, craniofacial malformation, long NICU stay duration, mechanical ventilation and drugs ototoxicity were found to be risk factors for failed transient evoked otoacoustic emissions hearing test in screened neonates in Children Welfare Teaching Hospital. The study recommends encouraging routine hearing screening programs for neonates especially those at risk like preterm, low birth weight, malformation and admission to NICUs. Larger national longitudinal multi-center studies applying other screening and diagnostic hearing tests must be supported.

\section{References:}

[1] Tucci DL, Merson MH, Wilson BS. A summary of the literature on global hearing impairment: current status and priorities for action. Otology \&Neurotology. 2010; 31:31-41.

[2] Nagapoornima P, Ramesh A, Rao S, Patricia PL, Gore M, Dominic M. Universal hearing screening. Indian J. Pediatr. 2007; 74:545-549.

[3] Paul AK. Early identification of hearing loss and centralized newborn hearing screening facility-the Cochin experience. Indian Pediatr. 2011; 48:355359.

[4] Sood M, Kaushal RK. Importance of newborn hearing screening. Indian Journal of Otolaryngology and Head \& Neck Surgery. 2009; 61:157-159.

[5] Biswas A. Clinical audio-vestibulometry for otologists and neurologists, assessing the deaf child, $3^{\text {rd }}$ edn. Bhalani Publishing House, Mumbai, 2007: 97-99.

[6] Joint Committee on Infant Hearing. Year 2007 position statement: principles and guidelines for early hearing detection and intervention programs. Pediatrics. 2007; 120:898-921.

[7] Northern JL, Downs MP. Hearing in Children. $6^{\text {th }}$ edition, plural publishing Inc., 2014: pp 385-90

[8] Kamal N. Newborn hearing screening: Opportunities and challenges. Egyptian Journal of Ear, Nose, Throat and Allied Sciences 2013; 14: 5558

[9] Haghshenas M, Zadeh PY, Javadian Y, Fard HA, Delavari K, Panjaki HSA, et al. Auditory Screening in Infants for Early Detection of Permanent Hearing Loss in Northern Iran. Annals of medical and health sciences research. 2014; 4(3): 340-344.

[10] Hilù MR, Zeigelboim BS. The knowledge and valorization of neonatal auditory screening and the early intervention of hearing loss. Revista CEFAC 2007; 9:563-570.

[11] Oliveira JS, Rodrigues LB, Aurélio FS, Silva $V B$. Risk factors and prevalence of newborn hearing loss in a private health care system of Porto Velho, Northern Brazil. Revista Paulista de Pediatria. 2013; 31(3):299-305.

[12] Gouri ZU, Sharma D, Berwal PK, Pandita A, Pawar S. Hearing impairment and its risk factors by 
hearing screening among neonates.

newborn screening in north-western India. Maternal Health, Neonatology and Perinatology 2015; 1(17): 1-8. Available

at: https://doi.org/10.1186/s40748-015-0018-1

[13] Pourarian S, Khademi B, Pishva N, Jamali A. Prevalence of Hearing Loss in Newborns Admitted to Neonatal Intensive Care Unit. Iranian Journal of Otorhinolaryngology. 2012; 24(68):129-134.

[14] Olusanya BO, Wirz SL, Luxon LM. Communitybased infant hearing screening for early detection of permanent hearing loss in Lagos, Nigeria: a crosssectional study. Bull. W. H. O. 2008; 86(12):956-963. [15] Habib HS, Abdel gaffar H. Neonatal hearing screening with transient evoked otoacoustic emissions in Western Saudi Arabia. Int J Pediatr Otorhinolaryngol 2005; 69(6):839-842.

[16] Kumar P, Adhisivam B, Bhat VB, Bharathi B, Francis $F$, Mondal N. Screening for Hearing Loss among High Risk Neonates? Experience from a Tertiary Care Center. Current Pediatric Research 2016; 20(1). Available at: www.alliedacademies.org/.../screening-for-hearingloss-among-high

[17] Harvey C. New born hearing screening. Aust Prescr 2003; 26:82-87.

[18] Margaret AK. Neonatal hearing screening. Pediatr Clin N Am 2003; 50:301-313.

[19] John M, Balraj A, Kurien M. Neonatal screening for hearing loss: pilot study from a tertiary care centre. Indian J Otolaryngology and Head \& Neck Surgery 2009; 61:23-26.

[20] Downs SM, Kemper AR. A cost-effectiveness analysis of new born hearing screening strategies. Am. J. Dis. Child. 2000; 154:484-488.

[21] Silva GC, Delecrode CR, Kemp AT, Martins F, Cardoso ACV. Transient Evoked and Distortion Product Otoacoustic Emissions in a Group of Neonates. International Archives of Otorhinolaryngology 2015; 19(3):255-258

[22] Waters TP, Silva N, Denney JM, Sciscione AC, Paul DA. Neonatal hearing assessment in very low birth weight infants exposed to antenatal steroids. J. Perinatol. 2008; 28(1):67-70.

[23] Matthews SG. Antenatal glucocorticoids and programming of the developing CNS. Pediatr. Res. 2000; 47: 291-300.

[24] Onoda RM, Azevedo MF, Santos AM. Neonatal Hearing Screening: failures, hearing loss and risk indicators. Brazilian Journal of Otorhinolaryngology. 2011; 77(6):775-783.

[25] Cristobal R, Oghalai JS. Hearing loss in children with very low birth weight: current review of epidemiology and pathophysiology. Archives of disease in childhood-Fetal and neonatal edition. 2008; 93(6):F462-F468.

[26] Jiang ZD, Brosi DM, Wilkinson AR. Hearing impairment in preterm very low birthweight babies detected at term by brainstem auditory evoked responses. Acta Paediatrica 2001; 90:1411-1415.
[27] Karaca ÇT, Oysu Ç, Toros SZ, Naiboğlu B, Verim A. Is Hearing Loss in Infants Associated With Risk Factors? Evaluation of the Frequency of Risk Factors. Clin. Exp. Otorhinolaryngol. 2014; 7(4):260-263.

[28] Shrikrishna BH, Deepa G. Study of association of family history and consanguinity with congenital hearing loss. International Journal of Otorhinolaryngology and Head and Neck Surgery 2016; 2 (2): 61-65.

[29] Lunardi S, Forli F, Michelucci A, Liumbruno A, Baldinotti F, Fogli A, et al. Genetic Hearing Loss Associated with Craniofacial Abnormalities. Hearing Loss 2012; 33: 399-406.

[30] Barboza ACS, de Resende LM, Ferreira DBC, Lapertosa CZ, Carvalho SAS. Correlation between hearing loss and risk indicators in a neonatal hearing screening reference service. AudiologyCommunication Research. 2013; 18(4):285-292.

[31] Paludetti G, Conti G, Di Nardo W. Infant hearing loss: from diagnosis to therapy Official Report of XXI Conference of Italian Society of Pediatric Otorhinolaryngology. Acta Otorhinolaryngologica Italica. 2012; 32(6):347-370. [32] AminiE, Farahani ZK, Samani MR. Assessment of Hearing Loss by OAE in Asphyxiated Newborns. Iranian Red Crescent Medical Journal 2014; 16(1):e6812.

[33] Rastogi S, Mikhael M, Filipov P, Rastogi D. Effects of ventilation on hearing loss in preterm neonates: Nasal continuous positive pressure does not increase the risk of hearing loss in ventilated neonates. Int J Pediatric Otorhinolaryngology 2013; 77(3):402-406.

[34] So TY. Use of Ototoxic Medications in Neonates: The Need for Follow-Up Hearing Test. The Journal of Pediatric Pharmacology and Therapeutics 2009; 14(4):200-203.

[35] Fligor BJ, Neault MW, Mullen CH. Factors associated with sensorineural hearing loss among survivors of extracorporeal membrane oxygenation therapy. Pediatrics 2005; 115:1519-1528.

[36] Kim SH, Choi BY, Park J, Jung EY, Cho SH, Park KH. Maternal and Placental Factors Associated with Congenital Hearing Loss in Very Preterm Neonates. Pediatrics \&Neonatology 2017; 58(3):236-244.

[37] Wickremasinghe AC, Risley RJ, Kuzniewicz $M W, W u Y W$, Walsh EM, Wi S, et al. Risk of Sensorineural Hearing Loss and Bilirubin Exchange Transfusion Thresholds. Pediatrics 2015; 136 (3): 505 512. 


\section{عوامل اختطار عيوب السمع وعلاقتها بنتيجة فحص السمع بين الولدان}

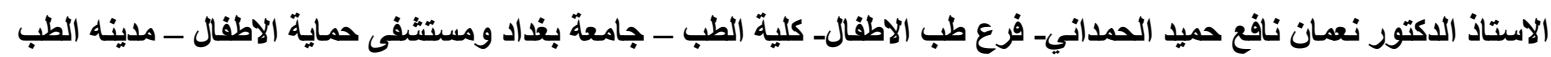

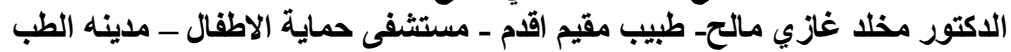

الخلاصة:

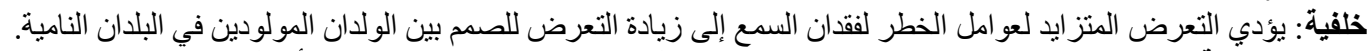

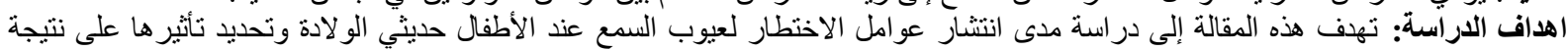

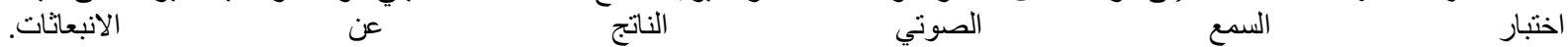
الطريقة: أجريت هذه الدر اسة الطوليه لمدة سنة واحدة. تم تسجيل الخصائص الديموغر افية وبعض عو امل الاختطار ـ و إذا لم يتمكنو المن اجنياز

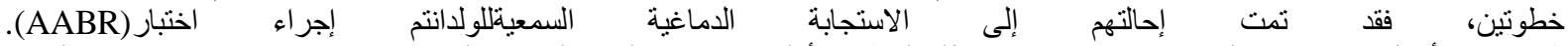

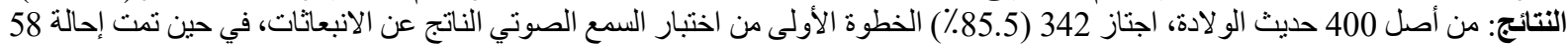

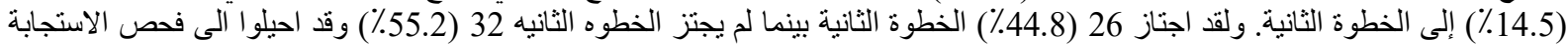

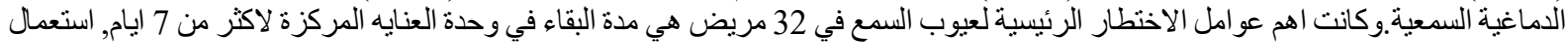

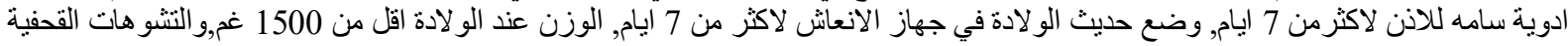

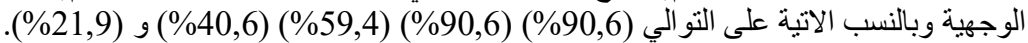

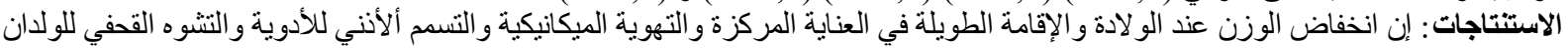

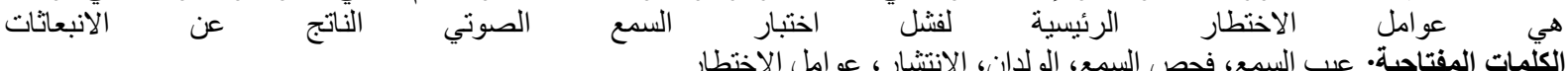

